\title{
Prevalence and Risk Factors of Teenage Pregnancy in Liberia: Evidence from Demographic Health Survey
}

\author{
Standee P. Weah ${ }^{1 *}$, Suresh Jungari ${ }^{2}$, Bal Govind Chauhan ${ }^{3}$ and Sosanwo Tobi Samson ${ }^{4}$ \\ ${ }^{I}$ Master of Public Health, Interdisciplinary School of Public Health, SavitribaiPhule Pune University, Pune, India City: Pune, \\ Country: India \\ ${ }^{2}$ Assistant Professor, Department of Public health \& Mortality and Studies, International Institute for Population Sciences, \\ Mumbai, India. City: Mumbai, Country: India \\ ${ }^{3}$ Assistant Professor, Population Research Centre, Gokhle Institute of Economics, Pune, India City: Pune, Country: India \\ Corresponding Author*
}

\begin{abstract}
Introduction:The rate of adolescent pregnancy varies enormously between countries and within countries. Teenage pregnancy is most common in lower-income and less-educated communities. Adolescent pregnancy is a significant public health concern in Liberia, posing an economic and social burden. This study is aimed at finding the prevalence and examining the risk factors of teenage pregnancy in Liberia.
\end{abstract}

Method:The data for this present study was from the fifth round of Liberia's Demographic and Health Survey, 2019-2020. The participants included in this study were 1,657 women aged 15 to 19 years. This study used descriptive statistics and binary logistic regression techniques to assess the effects of demographic, socioeconomic, and reproductive health indicators on adolescent pregnancy.

Results: The study found that $30.3 \%$ of teenage women aged 15 to 19 years had begun childbearing during the survey period. Age $(\mathrm{OR}=6.9 ; \mathrm{p}<0.001)$, marital status $(\mathrm{OR}=5.8 ; \mathrm{p}<0.001)$, teenage women living in the south-central region $(O R=1.057$; $>0.001)$, non-use of contraception $(\mathrm{OR}=2.53$; $\mathrm{p}<0.001)$, and teenage women who knew contraceptive methods $(\mathrm{OR}=2.86 ; \mathrm{p}>$ $0.001)$ were all significantly associated with teenage pregnancy in Liberia.

ConclusionTeenage pregnancy is common in Liberia. Lack of education, early marriages and cohabitation, contraceptive nonuse, rural location, and early sexual initiation are all factors that contribute to teen pregnancies. To lower the high prevalence of adolescent pregnancy and its consequences, intervention measures promoting contraception use, preventing early sexual initiation, limiting early marriages, and creating family planning clinics, primarily in rural regions, are strongly recommended.

Keywords: Prevalence, Teenage, Pregnancy, Risk factors

\section{INTRODUCTION}

A dolescent pregnancy is a pregnancy that occurs between the ages of 10 and 19 years. (Ganchimeg et al., 2014). According to WHO (2016), approximately 21 million girls aged 15-19 years become pregnant in developing countries each year, with around 12 million giving birth. Pregnancy among adolescents is a global public health issue that affects countries of all economic levels. Poor health, social and economic burden and low educational outcomes are significant consequences of teenage pregnancy. Teen pregnancies are similar in disadvantaged communities worldwide due to poverty, a lack of education, and a lack of job opportunities. Teenage pregnancies are associated with high maternal and child morbidity and mortality (WHO 2017). Adolescent fertility, especially among the youngest age groups, causes severe adverse health hazards to both the mother and the child and limits educational and employment options for young women (Nove et al., 2014). Adolescent pregnancy has long-term societal consequences for adolescents, their children, their families, and the communities in which they live. The children of teenage parents are more likely to struggle academically and drop out of high school. They also have higher health problems, are more likely to be incarcerated during their youth, and give birth while still in their adolescent years (Perper et al., 2010). According to WHO 2015 reports, the global adolescent birth rate is around 42.5 births per 1,000 girls. With the western Pacific having the lowest rate (14.4 births per 1,000 girls), Europe (17.1 per 1,000 girls), Southeast Asia (26.1 births per 1,000 girls), the Americas (49.9 births per 1,000 girls), the Eastern Mediterranean region (46.5 births per 1,000 girls), and Africa, having the highest rate (46.5 births per 1,000 girls).

The UNFPA report stated that approximately 14 million pregnancies occur in Sub-Saharan Africa every year, With about half of these pregnancies occurring among women aged 15-19. Almost one-tenth of all births are to women under 20 years of age. Developing countries account for more than $90 \%$ of these births (WHO 2017). In developing countries, married females account for over $90 \%$ of teenage pregnancies, and the majority of these married teenage pregnancies are intended (WHO, 2014). Is due to their extensive sex exposure and the need to produce quickly after marriage. Many African traditional groups have a reputation for pressuring adolescent girls to marry young. Often, early pregnancies are encouraged by cultural influences and familial pressure after marriage (Inyang et al., 2018).

Further research found that teenage fertility is high in countries where the Islamic religion is primarily practised, such as Cameroon, the Chad Republic, Niger, Liberia, Nigeria, and the rest of North Africa (Dahl 2010). Hence, due 
to early marriages, one out of every five teenage girls in these countries is sexually active by 15 , and one out of every five by 18 becomes pregnant (Patra, S., \& Singh 2013).

Liberia is a low-socioeconomic country; therefore, teenage pregnancies are more likely among the poor and the rural population. The rate of teen pregnancy in Liberia is of concern due to a lack of sex education, awareness and use of contraceptive methods, and a higher rate of early cohabitation, especially in rural areas. From Liberia's Demography and Health survey results, $31 \%$ of women aged 15 to 19 have started childbearing. The proportion of young women who have begun childbearing has increased rapidly with age, from $4 \%$ at 15 to $55 \%$ at 19 . It also claims that teenagers with no education $(47 \%)$ are more likely than those with some level of education to have begun childbearing (20\%-31\%). In addition, teenagers in the lowest wealth quintiles are more likely to have children (40\%-42\%). Hence, since 2013, Liberia's teenage fertility rate has decreased slightly, from $31 \%$ to $30 \%$. (LISGIS, 2013). There is limited evidence on factors associated with teen pregnancies and regional differences in Liberia. Therefore, this study determines the prevalence and risk factors of teenage pregnancy. Further examines the sexual and reproductive factors associated with adolescent pregnancy in Liberia.

\section{METHODOLOGY}

\section{Research design}

This study was conducted in Liberia using a population-based cross-sectional survey between mid-September and midOctober 2019.

\section{Study settings}

Liberia formally called the Republic of Liberia, got independence on July 26, 1847. Liberia is a country located on the West coast of Africa. It has around 5 million inhabitants and occupies an area of 111,369 square kilometres (43,000 sq. mi). The official language is English, but there are 16 indigenous languages spoken. Liberia is divided into 15 counties with subdivisions into districts and clans. The capital city is Monrovia.

\section{Sampling techniques}

The 2008 National Population and Housing Census (NPHC), conducted by the LISGIS, used as a sampling frame to carry out this survey. The first stage involved selecting sample points (clusters) that consist of the Enumeration area. EAs were selected based on a probability proportional to their size within each sampling stratum. The second stage involved systematic sampling of households. Household listing in all of the identified clusters was collected. From all of these clusters, 30 homes were sampled with an equal probability systematic selection process. Total 9,745 households were selected, and 9,207 of these households had participants living in at the time of the survey. Of the occupied households, 9,068 were successfully interviewed, yielding a response rate of $99 \%$. In the interviewed households, 8,364 women aged 15-49. were identified as individual interviewers; of the total identified women, 8,065 were successfully interviewed, yielding a response rate of $96 \%$. Further, a total of 4,527 men were eligible for individual interviews; 4,249 of these men were interviewed, producing a response rate of $94 \%$. The detailed methodology is in LISGIS, 2021.

\section{Data source}

The present study utilized the data from the fifth round of the Liberia Demographic Health Survey (LDHS-VI) conducted in 2019-20 implemented by the Liberia Institute of Statistics and Geo-Information Services (LISGIS) under the stewardship of the Ministry of Health (MOH) and the Government of Liberia. LDHS-IV is considered a resource for the new sixth National Health Strategic Plan (NHSP) 2017-2021. The LDHS, 201920 , followed a stratified two-stage cluster design.

\section{Statistical analysis}

The researchers employed univariate, bivariate, and multivariate data analysis methodologies. A chi-square test was used in bivariate analyses to assess the connection between the dependent variables (teenage pregnancy) and each explanatory variable. In multivariate analysis, bivariate logistic regression found the variables linked to teen pregnancy. The multivariate results was expressed as odds ratios with a $95 \%$ confidence range. We analyzed this data using IBM 20.0 SPSS (Statistical Package for the Social Sciences) software.

\section{Ethical consideration}

Before obtaining the data, a written communication from the Department of Health and sciences was severed to the Liberia Institute of Statistics and Geo-information Services(LISGIS) requesting permission to use the data. All data obtained were used straightly for the research.

\section{RESULTS}

Table 1. Sample Distribution of participants in Liberia DHS 2019-2020

\begin{tabular}{|c|c|c|}
\hline Background Characteristics & $\%$ & Total \\
\hline Age & & \\
\hline $15-17$ & 58.7 & 973 \\
\hline $18-19$ & 41.3 & 684 \\
\hline Level of Education & & \\
\hline No Education & 10.4 & 172 \\
\hline Primary & 40.1 & 665 \\
\hline Secondary/Higher & 49.5 & 820 \\
\hline Marital Status & & \\
\hline Never Married & 86.4 & 1431 \\
\hline Married & 1.3 & 22 \\
\hline Currently working & & \\
\hline No & 32.6 & 541 \\
\hline
\end{tabular}




\begin{tabular}{|c|c|c|}
\hline Yes & 67.4 & 1116 \\
\hline \multicolumn{3}{|l|}{ Wealth Index } \\
\hline Poorest & 13.6 & 225 \\
\hline Poorer & 16.7 & 276 \\
\hline Middle & 21.8 & 362 \\
\hline Richer & 24.2 & 401 \\
\hline Richest & 23.7 & 393 \\
\hline \multicolumn{3}{|l|}{ Region } \\
\hline North West & 8.1 & 134 \\
\hline South Central & 51.8 & 859 \\
\hline South East A\&B & 11.6 & 193 \\
\hline North Central & 28.4 & 471 \\
\hline \multicolumn{3}{|l|}{ Religion } \\
\hline Christian & 81.4 & 1349 \\
\hline Muslim & 16.5 & 273 \\
\hline Traditional/No religion/others & 2.1 & 35 \\
\hline \multicolumn{3}{|l|}{ Place of Residence } \\
\hline Urban & 64.4 & 1067 \\
\hline Rural & 35.6 & 590 \\
\hline \multicolumn{3}{|l|}{ Media Exposure } \\
\hline Not Exposed & 71.9 & 1192 \\
\hline Exposed & 28.1 & 465 \\
\hline \multicolumn{3}{|l|}{ Age at First sex } \\
\hline $10-14$ & 26.6 & 305 \\
\hline $15-18$ & 73.4 & 840 \\
\hline \multicolumn{3}{|l|}{ Knowledge of contraceptive Method } \\
\hline Knows no method & 5.1 & 84 \\
\hline Knows Traditional/folk/modern & 94.9 & 1573 \\
\hline
\end{tabular}

\begin{tabular}{|c|c|c|}
\hline Unmet needs of contraceptive & & \\
\hline Yes & 26.3 & 735 \\
\hline No & 73.7 & 919 \\
\hline Contraceptive use & & \\
\hline User & 18.6 & 308 \\
\hline Non-User & 81.4 & 1349 \\
\hline Ever had a pregnancy terminated & & \\
\hline No & 95.8 & 1587 \\
\hline Yes & 4.2 & 70 \\
\hline Total & 100 & 1657 \\
\hline
\end{tabular}

Note: Cases may not be equal due to missing values. Percentage and numbers are weighted.

Table 1 shows the distribution of teenage women. This table shows that $58.7 \%$ of teenage women belong to the $15-17$ years age group, $41.3 \%$ of the teenagers belongs to the $18-19$ years age group. Nearly $50 \%$ of the respondents had completed a secondary or higher level of education, and only $10.4 \%$ were illiterate. $86.4 \%$ of the respondents were never married, while only $1.3 \%$ were married, and $64.7 \%$ responded as currently working. The majority of the respondents $(24.2 \%)$ were from the rich wealth index category whereas, $13.6 \%$ were from the poorer wealth index. Around $64.4 \%$ of the respondents reside in the urban area, $51.8 \%$ of the respondents belonged to the south-central region of Liberia, Christianity was the dominant religion (81.4\%), whereas $16.5 \%$ of the respondents practised Islamism. About $72 \%$ of the respondents had no exposure to any media (radio, $\mathrm{TV}$, newspapers), and $73.4 \%$ reported having their first sex were between 15-18 years. Nearly $95 \%$ knew contraceptive methods. Even though participants were aware of contraceptives, $81.4 \%$ of young women did not use them, and $26.3 \%$ of respondents had unmet contraceptive needs. $4.2 \%$ of the respondents had a pregnancy terminated.

Table 2. Sociodemographic and sexual reproductive health Characteristics of teenage women in Liberia DHS 2019-2020

\begin{tabular}{|c|c|c|c|c|}
\hline Background Characteristics & $\begin{array}{l}\% \text { of teenage women } \\
\text { who had live birth }\end{array}$ & $\begin{array}{c}\% \text { of Teenage women } \\
\text { who are pregnant with } \\
\text { first child } \\
\end{array}$ & $\begin{array}{c}\% \text { of Teenage women } \\
\text { who have begun } \\
\text { childbearing }\end{array}$ & Total \\
\hline Age & $* * *$ & $* * *$ & $* * *$ & \\
\hline $15-17$ & 12.5 & 3.9 & 16.4 & 973 \\
\hline $18-19$ & 43.2 & 7.0 & 50.2 & 684 \\
\hline Level of Education & $* * *$ & $* * *$ & $* * *$ & \\
\hline No Education & 38.4 & 8.1 & 46.5 & 172 \\
\hline Primary & 26.4 & 4.1 & 30.5 & 665 \\
\hline Secondary/Higher & 21.4 & 5.4 & 26.8 & 820 \\
\hline Marital Status & $* * *$ & ns & $* * *$ & \\
\hline Never Married & 18.7 & 3.8 & 22.5 & 1431 \\
\hline Married & 87.6 & 0.8 & 88.4 & 22 \\
\hline Currently working & $* * *$ & ns & $* * *$ & \\
\hline No & 19.9 & 5.3 & 25.2 & 1116 \\
\hline
\end{tabular}




\begin{tabular}{|c|c|c|c|c|}
\hline Yes & 36.0 & 4.9 & 40.9 & 541 \\
\hline Wealth Index & $* * *$ & $* * *$ & $* * *$ & \\
\hline Poorest & 35.8 & 6.2 & 42.0 & 225 \\
\hline Poorer & 34.0 & 6.0 & 40.1 & 276 \\
\hline Middle & 33.8 & 6.5 & 40.3 & 362 \\
\hline Richer & 22.8 & 5.8 & 28.6 & 401 \\
\hline Richest & 7.3 & 2.2 & 9.5 & 393 \\
\hline Region** & $* *$ & $\mathrm{~ns}$ & $* *$ & \\
\hline North West & 30.2 & 6.9 & 37.1 & 134 \\
\hline South Central & 21.6 & 4.5 & 26.1 & 859 \\
\hline South East A\&B & 24.1 & 6.1 & 30.2 & 193 \\
\hline North Central & 30.6 & 5.6 & 36.2 & 471 \\
\hline Religion & Ns & $\mathrm{ns}$ & ns & \\
\hline Christian & 26.4 & 4.9 & 31.3 & 1349 \\
\hline Muslim & 19.6 & 6.0 & 25.6 & 273 \\
\hline Traditional/No religion/others & 20.2 & 8.1 & 28.3 & 35 \\
\hline Place of Residence & $* * *$ & ns & $* * *$ & \\
\hline Urban & 21.5 & 4.3 & 25.8 & 1067 \\
\hline Rural & 31.8 & 6.7 & 38.5 & 590 \\
\hline Media Exposure & Ns & $\mathrm{ns}$ & $\mathrm{ns}$ & \\
\hline Not Exposed & 26.5 & 5.4 & 32.0 & 1192 \\
\hline Exposed & 21.6 & 4.5 & 26.2 & 465 \\
\hline Age at First sex & Ns & ns & ns & \\
\hline $10-14$ years & 46.1 & 9.2 & 55.4 & 305 \\
\hline $15-18$ years & 32.9 & 6.8 & 39.8 & 840 \\
\hline Knowledge of contraceptive method & $* * *$ & ns & $* * *$ & \\
\hline Knows no method & 3.4 & 1.7 & 5.1 & 84 \\
\hline Knows Traditional/folk/modern & 26.3 & 5.4 & 31.7 & 1573 \\
\hline Unmet needs of contraceptive & $* * *$ & $\mathrm{~ns}$ & $* * *$ & \\
\hline Yes & 13.5 & 4.5 & 18.0 & 735 \\
\hline No & 34.6 & 5.8 & 40.3 & 919 \\
\hline Contraceptive use & $* * *$ & & $* * *$ & \\
\hline User & 29.4 & 0.0 & 29.4 & 308 \\
\hline Non-User & 24.2 & 6.3 & 30.5 & 1349 \\
\hline Ever had a pregnancy terminated & $* * *$ & $\mathrm{~ns}$ & $* * *$ & \\
\hline No & 25.5 & 4.8 & 30.3 & 1587 \\
\hline Yes & 17.6 & 14.4 & 32,0 & 70 \\
\hline Total & 25.2 & 5.3 & 30.3 & 1657 \\
\hline
\end{tabular}

Note: Cases may not be equal due to missing values.Chi-square showing the degrees of significant: $* \mathrm{p}<0.1, * *<0.05, * * *<0.001$

a. Sociodemographicand sexual reproductive health characteristics of the respondents

Table 2 shows the distribution of teenage pregnancy by their socio-economic, demographic and reproductive characteristics. Overall, $25.2 \%$ of the teenage women had a live birth, $5.3 \%$ were pregnant for the first time, and $30.3 \%$ had already begun childbearing at the time of the survey. The indicator, teenage women who had begun childbearing in their teen years, is the combination of teenage women who have 
had a live birth and those pregnant for the first time. All adolescent pregnancy indicators were prevalent in the age group 18-19 years, teenagers with no or little education, married adolescents, those who worked, and those in the poorest wealth quintile category. For example, half of the teenage women in the $18-19$ age group $(50.2 \%)$ have begun childbearing, compared to $16.4 \%$ in the $15-17$ age group, and $46.5 \%$ of teenage women with no education have begun childbearing, compared to those who have finished secondary/higher-level education (26.4\%).

Similarly, $42 \%$ of teenage women in the lowest wealth quintile have begun childbearing, compared with $9.5 \%$ of those in the highest quintile as far as regions of residence is a concern, the percentage of teenagers who have started childbearing ranges from $26.1 \%$ in Southcentral to $37.1 \%$ in North West. The prevalence of teenage pregnancy was higher $(31.3 \%)$ among those that practised Christian religion, reside Determinant of teenage pregnancy in Liberia, 2019-20 in rural areas $(38.5 \%)$ and are not exposed to any media $(32.0 \%)$ than their counterparts.

The sexual and reproductive factors show that teenage women who had sex before 15 years were $55.4 \%$. $46.1 \%$ of those who began childbearing had a live birth, and $9.2 \%$ were pregnant with their first child. Among those who knew contraceptive methods, $26.3 \%$ had live births, $5.4 \%$ were pregnant with their first child, and $31.7 \%$ had begun childbearing. Teenage pregnancy was higher among those who had unmet need of contraceptives and currently not using any method of contraception. For illustration, $34.6 \%, 5.8 \%$ and $40.3 \%$ of the teenage women had a live birth, were pregnant the first time and have begun childbearing, respectively, among those who had no unmet need of contraceptives. Similarly, among nonuser contraception, $30.5 \%$ of teenage women have started childbearing, whereas $29.4 \%$ are contraceptive users.

Table 3. Logistic regression result for determinats of teenage Pregnancy in Liberia, DHS 2019-2020.

\begin{tabular}{|c|c|c|c|c|c|c|}
\hline & \multicolumn{2}{|c|}{ Model 1} & \multicolumn{2}{|c|}{ Model 2} & \multicolumn{2}{|c|}{ Model 3} \\
\hline background characteristics & OR & $95 \% \mathrm{CI}$ & OR & $95 \% \mathrm{CI}$ & OR & $95 \% \mathrm{CI}$ \\
\hline \multicolumn{7}{|l|}{ Age } \\
\hline \multicolumn{7}{|l|}{$15-17 ®$} \\
\hline $18-19$ & $6.008 * * *$ & $(4.459,8.094)$ & & & $6.941 * * *$ & $(4.647,10.366)$ \\
\hline \multicolumn{7}{|l|}{ Education } \\
\hline \multicolumn{7}{|l|}{ No Education $®$} \\
\hline Primary & 0.892 & $(0.548,1.451)$ & & & 0.633 & $(0.342,1.172)$ \\
\hline Secondary/Higher & 0.870 & $(0.528,1.435)$ & & & 0.448 & $(0.238,0.843)$ \\
\hline \multicolumn{7}{|l|}{ Marital Status } \\
\hline \multicolumn{7}{|l|}{ Never Married $\AA$} \\
\hline Married & $15.998 * * *$ & $(4.028,63.535)$ & & & $5.832 * * *$ & $(1.415,24.035)$ \\
\hline \multicolumn{7}{|l|}{ Wealth Index } \\
\hline \multicolumn{7}{|l|}{ Poorest ${ }^{\circledR}$} \\
\hline Poorer & $1.123 * * *$ & $(0.695,1.815)$ & & & $1.479 * * *$ & $(0.863,2.537)$ \\
\hline Middle & 1.135 & $(0.688,1.872)$ & & & 2.072 & $(1.158,3.709)$ \\
\hline Richer & 0.753 & $(0.423,1.340)$ & & & 1.256 & $(0.652,2.421)$ \\
\hline Richest & 0.175 & $(0.089,0.343)$ & & & 0.333 & $(0.158,0.704)$ \\
\hline \multicolumn{7}{|l|}{ Region } \\
\hline \multicolumn{7}{|l|}{ North West ${ }^{\circledR}$} \\
\hline South Central & 1.092 & $(0.632,1.885)$ & & & 1.057 & $(0.558,2.000)$ \\
\hline South East A\&B & 0.960 & $(0.522,1.767)$ & & & 0.801 & $(0.398,1.614)$ \\
\hline North Central & 1.033 & $(0.600,1.779)$ & & & 0.874 & $(0.463,1.647)$ \\
\hline \multicolumn{7}{|l|}{ Currently working } \\
\hline \multicolumn{7}{|l|}{$\mathrm{No} \circledast$} \\
\hline Yes & 1.152 & $(0.860,1.545)$ & & & 1.071 & $(0.765,1.500)$ \\
\hline \multicolumn{7}{|l|}{ Place of Residence } \\
\hline Urban® & & & & & & \\
\hline
\end{tabular}




\begin{tabular}{|c|c|c|c|c|c|c|}
\hline Rural & 1.136 & $(0.766,1.684)$ & & & 1.023 & $(0.652,1.603)$ \\
\hline \multicolumn{7}{|l|}{ Media exposure } \\
\hline \multicolumn{7}{|l|}{ Exposed ${ }^{\circledR}$} \\
\hline Not exposed & 0.820 & $(0.585,1.150)$ & & & 0.745 & $(0.515,1.078)$ \\
\hline \multicolumn{7}{|l|}{$\begin{array}{l}\text { Sexual and Reproductive } \\
\text { Health Factors associated }\end{array}$} \\
\hline \multicolumn{7}{|l|}{ Age at First sex } \\
\hline \multicolumn{7}{|l|}{ 10-14® } \\
\hline $15-18$ & & & 0.550 & $(0.431,0.702)$ & $0.244 * * *$ & $(0.165,0.360)$ \\
\hline \multicolumn{7}{|l|}{ Knowledge of contraceptive } \\
\hline \multicolumn{7}{|l|}{ Know no method } \\
\hline $\begin{array}{c}\text { Knows } \\
\text { Traditional/folk/modern }{ }^{\circledR}\end{array}$ & & & 1.205 & $(0.340,4.273)$ & $2.861 * * *$ & $(0.443,18.463)$ \\
\hline \multicolumn{7}{|l|}{ Unmet needs } \\
\hline \multicolumn{7}{|l|}{ Yes® } \\
\hline No & & & 1.191 & $(0.891,1.592)$ & $2.701 * * *$ & $(1.775,4.111)$ \\
\hline \multicolumn{7}{|l|}{$\begin{array}{c}\text { Contraceptive use and } \\
\text { intention }\end{array}$} \\
\hline \multicolumn{7}{|l|}{ User® } \\
\hline Non- user & & & $2.480 * * *$ & $(1.835,3.352)$ & 2.531 & $(1.739,3.683)$ \\
\hline \multicolumn{7}{|l|}{ Ever terminated pregnancy } \\
\hline \multicolumn{7}{|l|}{$\mathrm{No} \circledast$} \\
\hline Yes & & & 0.566 & $(0.333,0.964)$ & 0.735 & $(0.361,1.494)$ \\
\hline
\end{tabular}

Note: level of significant: ${ }^{*} \mathrm{p}<0.1,{ }^{*} \mathrm{p}<0.05$ and $* * * \mathrm{p}<0.001$. OR: Oddsratio, @: reference category

A bivariate logistic regression analysis was employed to find the sociodemographic factors and the sexual and reproductive health risks that were linked to adolescent pregnancy. There were three different models used. In the absence of explanatory variables, Model one revealed that variation in teenage pregnancy was related to the distribution of primary sample units, model two included the sexual and reproductive health characteristics of teenage women. The final model consists of the probability of the two variables (Model 3). (Factors affecting socioeconomic, sexual, and reproductive health)

In the bivariate analysis, factors with P-values less than 0.02 included age, marital status, employment, level of education, place of residence, knowledge of contraceptive methods, wealth index, region, age at first sex, and unmet needs. After adjustment for probable confounders, P-values of less than 0.02 were used to group variables and input them into the logistic regression model. Age, marital status, knowledge of contraceptives, wealth index, age at first sex, and unmet needs were identified as statistically significant variables in the logistic regression model.

Regarding the individual predictor, the odds of having adolescent pregnancy in Liberia increased with age, with those aged 18-19 having approximately seven times higher odds of experiencing pregnancy $(\mathrm{OR}=6.9 ; 95 \% \mathrm{CI} ; 4.647$, 10.366, p-value 0.001). Teenagers who were married were five times more likely to become pregnant than those who were not married $(\mathrm{OR}=5.8 ; 95 \% \mathrm{CI} ; 1.415,24.035$, p-value 0.001). In addition, teenagers who belong to the middle wealth index were two times more likely to become pregnant than those who belong to the richer or richer wealth index $(\mathrm{OR}=2.07$; 95\% CI: $1.158,3.709)$. Teenagers from the southcentral region had a $57 \%$ or higher risk of becoming pregnant $(\mathrm{OR}=1.057 ; 95 \% \mathrm{CI}: 0.558,2.000)$. Also, teenage women who reside in the rural areas of Liberia had $23 \%$ higher chances of experiencing pregnancy $(\mathrm{OR}=1.023$, $95 \% \mathrm{CI}=0.652,1.603$ ). Adolescent women who knew contraceptive methods had two times higher odds of becoming pregnant $(\mathrm{OR}=2.86,95 \% \mathrm{CI}=0.443,18.463)$. On the other hand, the risk of teenage women becoming pregnant doubled among adolescents who had no unmet contraceptive need $(\mathrm{OR}=2.70 ; 95 \% \mathrm{CI}: 1.775,4.111)$. As well as those teenage women who were non-contraceptive users $(\mathrm{OR}=2.53$; 95\% CI: $1.739,3.683)$. The study also discovered a $24 \%$ reduction in teenage women who had their first sex before the age of 18 (OR=0.24; 95\% CI: $0.165,0.360)$, a $63 \%$ reduction in those with a primary education compared to those without $(\mathrm{OR}=0.63,95 \% \mathrm{CI}=0.342,1.172)$, and a $74 \%$ reduction in those who have no media exposure $(\mathrm{OR}=0.74,95 \% \mathrm{CI}=0.515$, 1.078).

Model one shows a $1.1 \%$ increase in the odds of teenage women who have started childbearing before the age of 19 compared to model three, which could be due to the increased 
variables in model three. Model three also shows a $2.5 \%$ decrease in marital status and a $0.3 \%$ increase in wealth index among poorer teenage women.

\section{DISCUSSION}

The global prevalence of teenage pregnancy varies considerably. Several factors, including sociodemographic, cultural, and sexual and reproductive health, Influenced this. The current study examined the prevalence and risk factors of teenage pregnancy in Liberia and found that the prevalence of teen pregnancy in Liberia is $30.3 \%$. Pregnancy among teenagers was linked to age, employment, contraceptive knowledge, marital status, education level, residency, unmet needs, and wealth index, and the results of this study are consistent with results from other studies conducted in various African countries such as Ethiopia (Habitu et al., 2017), Western Nigeria (Amoran, O. E. 2012), and Uganda (Akanbi, F. et al. 2016). The current and prior investigations identified similar sociodemographic, cultural, and individual teenage traits, which may account for the similarities.

Teenage pregnancy was more prevalent in rural regions than urban and among non-educated teenagers than educated adolescents, similar to studies in Ethiopia (Habitu et al., 2017; Ahinkorah et al., 2012). Teenage women who have ever had sex, married, or in a relationship are statistically more likely to become pregnant than other teenagers in Liberia. One of the reasons is that marriage and cohabitation increase adolescent females' desire to have children, thus increasing their chances of becoming pregnant. In most Sub-Saharan African nations, young women are encouraged to marry and start families, exacerbating the problem. The majority of young girls who marry early, have no education, originate from low-income families, and reside in rural areas are more likely to engage in behaviours that put them at risk of becoming pregnant (UNICEF 2014). Other research (Acharya et al., 2014; Kassa et al., 2018) has identified a link between adolescent pregnancy and child marriage. Another study found that some teenage females are forced into marriage or cohabitation (Mehra et al., 2018).

This study found that teenagers aware of contraception had a higher chance of getting pregnant. In contrast to common belief, contraceptive knowledge may have arrived after pregnancy has happened; this was similar to another study (Boamah et al., 2014), which explained that lack of awareness about the spectrum and use of contraceptive options and shallow information could be one reason. Other research suggests that pregnancy may have occurred despite contraceptive awareness due to a willingness or social pressure to become pregnant (Glassman et al., 2012). Therefore, condemning early sexual activity, pregnancy, and contraceptive usage by unmarried teenagers may be significant barriers to contraception use (Nalwadda et al., 2012).

Our study also found that having no unmet contraceptive needs was linked to adolescent pregnancy. Young females have likely altered fertility objectives following pregnancy, abortion, or motherhood, which explains the seemingly counterintuitive finding (Guzzo KB et al., 2019). Other possibilities include traditional or folkloric contraception use by adolescent girls rather than contemporary contraceptives. Contraception failure, inaccuracy and irregular condom usage, and contraceptive non-use contribute to an unintended pregnancy (Ajayi AI et al., 2016).

Finally, this study found a high prevalence of adolescent pregnancy among teenage girls who work, which is consistent with many other studies that have found that the risk of teen pregnancy is higher among adolescent girls who work (Odimegwu, C. et., al., 2016, Sheldon T., 2018), presumably because female adolescents who do not work are more likely to be in school, and they made have access to comprehensive sex education, which has proven to lower the risk of adolescent pregnancy (Carter D., 2012).

\section{Limitation}

Given the data's heterogeneity, the missing variables and composite data to investigate the influences on adolescent pregnancy in Liberia are limitations. Further, including teenagers who have ever had a pregnancy terminated as part of the teenage pregnancy measure is likely to bias the results. The data on pregnancy termination in the DHS is frequently of poor quality and under-reported. Moreover, some of the participants' questions were about concerns after the pregnancy, while others were about their present pregnancy. The latter group's reported knowledge and behaviour may have influenced their pregnancy. Finally, data on the explanatory variables included in this study, except age at first sex, correspond to the time of the surveys and may differ from the experience at the time of pregnancy. These can result in reverse causalities, such as when education ends, marriage occurs, or contraception knowledge gained after pregnancy.

\section{CONCLUSION}

The high prevalence of adolescent pregnancy in Liberia is a subject of alarm. Based on past research on the variables that contribute to teenage pregnancy and the harmful effects of doing so. According to our data, age, employment, marital status, education level, early sexual initiation, lack of contraceptive use, rural location, unmet needs, and wealth index all play a role in adolescent pregnancy in Liberia.

\section{RECOMMENDATIONS}

Substantial investment in national strategies, assessment, and adolescent sexual and reproductive health involvement is required to meet the SDG 3 target by 2030. Providing innovative techniques to encourage adolescents to participate in family planning activities are desperately needed. To promote family planning among youths, rural health care providers should make clinics and family planning centres more youth-friendly and increase community mobilization and information-education-communication (IEC) initiatives. 
Increase awareness about the risks and complications of teenage pregnancy through a sexual and reproductive health program in collaboration with schools, the private sector, and non-governmental organizations. Great effort into sex education at various institutions should be considered, and sex education should be a core course to learn, making sex education accessible to youth.

\section{ACKNOWLEDGEMENT}

We would also like to thank the MEASURE DHS Program and ICF International for the LDHS data usages. We would also like to acknowledge the teaching and non-teaching staff of the Interdisciplinary School of Health Science, SavitribaiPhule Pune University, Pune City, India.

\section{ETHICAL CONSIDERATION}

The present study is based on a secondary data set which is available in the public domain at https://dhsprogram.com/data/available-datasets.cfm.

\section{FUNDING}

This research received no specific grant from any funding agency in the public, commercial, or not-for-profit sectors for the research, authorship, and/or publication of this article.

\section{DECLARATION OF CONFLICTING INTERESTS}

The Authors declares that there is no conflict of interest.

\section{REFERENCES}

[1] Acharya, D. R., Bhattarai, R., Poobalan, A., Teijlingen, V. E., \& Chapman, G. (2014). Factors associated with teenage pregnancy in South Asia.

[2] Ahinkorah, B. O., Kang, M., Perry, L., Brooks, F., \&Hayen, A. (2021). Prevalence of first adolescent pregnancy and its associated factors in sub-Saharan Africa: A multi-country analysis. Plos one, 16(2), e0246308.

[3] Ajayi AI, Nwokocha EE, Akpan W, Adeniyi OV. Use of nonemergency contraceptive pills and concoctions as emergency contraception among Nigerian University students: results of a qualitative study. BMC Public Health. 2016;16(1):1046. pmid:27716213

[4] Akanbi, F., Afolabi, K., \&Aremu, A. (2016). Individual risk factors contributing to the prevalence of teenage pregnancy among teenagers at Naguru teenage center kampala, Uganda (Doctoral dissertation, Primary Healthcare: Open Access).

[5] Amoran, O. E. (2012). A comparative analysis of predictors of teenage pregnancy and its prevention in a rural town in Western Nigeria. International journal for equity in health, 11(1), 1-7.

[6] AyanawHabitu, Y., Yalew, A., \&AzaleBisetegn, T. (2018). Prevalence and factors associated with teenage pregnancy, northeast Ethiopia, 2017: A cross-sectional study. Journal of pregnancy, 2018.

[7] Boamah, E. A., Asante, K. P., Mahama, E., Manu, G., Ayipah, E. K., Adeniji, E., \&Owusu-Agyei, S. (2014). Use of contraceptives among adolescents in Kintampo, Ghana: a cross-sectional study. Open Access Journal of Contraception, 5, 7-15.

[8] Carter D. Comprehensive sex education for teens is more effective than abstinence. AJN The American Journal of Nursing. 2012;112(3):15. pmid:22373675

[9] Ganchimeg, T., Ota, E., Morisaki, N., Laopaiboon, M., Lumbiganon, P., Zhang, J., ... \& WHO Multicountry Survey on
Maternal Newborn Health Research Network. (2014). Pregnancy and childbirth outcomes among adolescent mothers: A World Health Organization multi-country study. BJOG: An International Journal of Obstetrics \&Gynaecology, 121, 40-48.

[10] Glassman, A. L., Silverman, R., \&McQueston, K. (2012). Adolescent fertility in low-and middle-income countries: effects and solutions. Center for Global Development Working Paper, (295).

[11] Guzzo KB, Hayford SR, Lang VW. Adolescent fertility attitudes and childbearing in early adulthood. Population research and policy review. 2019;38(1):125-52. pmid:31543558

[12] Inyang, B. A., Makondelele, R. M., Thobile, Z. P., \& Makgopa, M. (2018). The role of socio-cultural factors and parenting practices on the prevalence of teenage pregnancy in Vhembe district, Limpopo province. Journal of Sociology and Social Anthropology, 9(3), 69-79. https://doi.org/10.31901/24566764.2018/09.03.273

[13] Kassa, G. M., Arowojolu, A. O., Odukogbe, A. A., \&Yalew, A. W. (2018). Prevalence and determinants of adolescent pregnancy in Africa: a systematic review and meta-analysis. Reproductive health, 15(1), 1-17.

[14] Liberia Institute of Statistics, Geo-Information Services - LISGIS, Health Mo,Social Welfare/Liberia, National AIDS Control Program/Liberia, ICFInternational. Liberia Demographic and Health Survey 2013. Monrovia:LISGIS and ICF International; 2014.

[15] Mathews, T. J., \& MacDorman, M. F. (2012). Infant mortality statistics from the 2009 period linked birth/infant death data set. National Vital Statistics Reports, 61(8).

[16] Mehra, D., Sarkar, A., Sreenath, P., Behera, J., \&Mehra, S. (2018). Effectiveness of a community based intervention to delay early marriage, early pregnancy and improve school retention among adolescents in India. BMC Public Health, 18(1), 1-13.

[17] Nalwadda, G. K. (2012). Contraceptive Use among Young People in Uganda (Doctoral dissertation, Makerere University).

[18] Nove, A., Matthews, Z., Neal, S., \& Camacho, A. V. (2014). Maternal mortality in adolescents compared with women of other ages: Evidence from 144 countries. The Lancet Global Health, 2(3), e155-e164. https://doi.org/10.1016/S2214-109X(13)70179-7

[19] Odimegwu, C., \&Mkwananzi, S. (2016). Factors associated with teen pregnancy in sub-Saharan Africa: a multi-country crosssectional study. African Journal of Reproductive Health, 20(3), 94-107.

[20] Patra, S., \& Singh, R. K. (2013). Levels, Trends, Determinants and Consequences of Adolescent Pregnancy in India. In The 27th IUSSP International Population Conference.

[21] Perper, K., \&Manlove, J. (2010). Diploma attainment among teen mothers.

[22] Sheldon, T. (2018). Could Dutch style sex education reduce pregnancies among UK teenagers? BMJ, 360 .

[23] UNICEF (2008). Young people and family planning: Teenage pregnancy. Malaysia: UNICEF.

[24] UNICEF and Plan International. Experiences and accounts of pregnancy among adolescents. Panama: UNICEF; 2014. Available at:

https://www.unicef.org/lac/UNICEF_PLAN_pregnancy_amongst_ adolescents_2015.pdf

[25] Were, M. (2007). Determinants of teenage pregnancies: The case of Busia District in Kenya. Economics \& Human Biology, 5(2), 322-339.

[26] WHO. Adolescents: Health Risks and Solutions. Geneva: World Health Organization; 2017. Available from http://www.who.int/mediacentre/factsheets/fs345/en/

[27] WHO. Global health estimates 2015: deaths by cause, age, sex, by countryand by region, 2000-2015. Geneva: World Health Organization; 2016.

[28] World Health Organization (2014) Adolescent pregnancy. 